\title{
Eficácia e evolução dos indicadores socioeconômicos de famílias beneficiadas pelo programa de combate à pobreza rural /Projeto São José no Estado do Ceará
}

\author{
Ahmad Saeed Khan* \\ Lucia Maria Ramos Silva**
}

Resumo: Objetivou-se verificar a evolução de indicadores socioeconômicos das famílias beneficiadas pelo programa de Combate à Pobreza Rural. Para tanto, foram feitas comparações intertemporais (ano de 1998 - ano base - e ano de 2001) de informações levantadas com beneficiários de subprojetos selecionados (abastecimento de água, eletrificação rural, mecanização agrícola e Ação Fundiária) em 27 comunidades no Estado do Ceará. Os resultados permitem concluir que houve melhorias, entre outras, no nível de educação, nas condições de moradia, nos hábitos alimentares, na aquisição de bens duráveis e na renda dos beneficiários entre os dois períodos e, ainda, observou-se que os beneficiados apresentaram "renda capita" superior à renda "renda capita" da população rural do Estado do Ceará.

Palavras-chave: Eficácia, Pobreza, Ceará

Classificação JEL: Q12, Q28

\footnotetext{
* Professor Titular do Departamento de Economia Agrícola (DEA) da Universidade Federal do Ceará (UFC), bolsista do CNPq. saeed@ufc.br

** Professora Livre Docente do Departamento de Economia Agrícola (DEA) da Universidade Federal do Ceará (UFC). lramos@ufc.br
} 
1038 - Eficácia e evolução dos indicadores socioeconômicos de famílias beneficiadas pelo programa de combate à pobreza rural/Projeto São José no Estado do Ceará

Abstract: The objective of this study was to verify the evolution of economic indicators of the families, living in 27 communities, benefited by Rural Poverty Reduction Program in the state of Ceará. For this purpose, the years of 1998 (base year) and 2001 were selected. The information was obtained from the beneficiaries of projects such as water supply, rural electrification, agriculture mechanization and land reform. The results allowed to conclude that there was an improvement in living conditions, acquisition of durable goods and income level of population benefited by the Program. Also, comparison between per capita income of these families and rural population of the state was made.

Key words: Efficacy, welfare, Ceará

JEL classification: Q12; Q28

\section{Introdução}

Um dos sérios problemas enfrentados por grande parte dos países é a desigualdade na distribuição de riqueza. A luta contra a pobreza tem sido um desafio para muitos governos em todo o mundo (BANCO MUNDIAL 2001). No Brasil foram desenvolvidas políticas visando minorar estes problemas e possibilitar melhores condições de vida para a população de menor poder aquisitivo e contribuir para a sustentabilidade da agricultura familiar (MACHADO, 1998).

Neste contexto, o Estado do Ceará criou o Programa de Apoio ao Pequeno Produtor (PAPP). Em 1995, após alguns ajustes, este programa passou a denominar-se Projeto São José (PSJ), cujo objetivo principal era a implementação de ações de desenvolvimento sustentável no estado, com participação ativa das comunidades, com vistas a aumentar o acesso das populações rurais mais pobres às atividades de geração de emprego e renda, assim como a provisão de serviços sociais básicos e de infra-estrutura como meios para a redução da pobreza rural. Em 1996, o Projeto São José passou a denominar-se Programa de Combate à Pobreza Rural (PCPR). Nos anos de 1996 a 1998 foram financiados e implantados vários subprojetos relacionados à infra-estrutura, produção e desenvolvimento social em comunidades 
distribuídas em municípios situados em diferentes microrregiões do estado (CEARÁ, 1998).

É importante, portanto, após este período conhecer a eficácia deste programa e os benefícios que os recursos alocados nos subprojetos trouxeram para o bem-estar das famílias. Espera-se que os resultados alcançados neste estudo permitam avaliar se a qualidade e suficiência das ações empreendidas pelo Governo obtiveram os resultados esperados, ou seja, tenha havido melhorias expressas através de indicadores socioeconômicos da população beneficiada pelo Programa de Combate à Pobreza Rural (PCPR) / Projeto São José (PSJ).

\section{Objetivos}

Identificar e analisar a eficácia do Programa de Combate à Pobreza Rural - PCPR/Projeto São José - (PSJ) e a evolução de indicadores socioeconômicos das famílias entrevistadas dos beneficiários através de subprojetos de Abastecimento de Água, Ação Fundiária, Mecanização Agrícola e Eletrificação Rural no Estado do Ceará.

\section{Metodologia}

Foi utilizada análise tabular e descritiva, com a apresentação, sempre que possível, das freqüências relativas e absolutas dos dados obtidos por meio de entrevistas diretas com chefes das famílias beneficiadas nos subprojetos selecionados. Foram também usadas algumas ferramentas estatísticas, tais como o teste "t" de Student, o teste F de Snedecor e teste de Mann-Whitney U. Para identificação da evolução dos indicadores, foram feitas comparações entre as informações levantadas sobre os beneficiários e suas famílias (amostradas) relativas ao ano de 2001 (coletadas em março de 2002) com as informações colhidas em novembro de 1998.

\section{Amostra}

Na seleção dos subprojetos levou-se em consideração a concentração do número de famílias beneficiadas. Desta forma, foram seleciona-

RER, Rio de Janeiro, vol. 45, no 04, p. 1037-1053, out/dez 2007 - Impressa em novembro 2007 
dos quatro tipos de subprojetos: abastecimento de água, ação fundiária, eletrificação rural e mecanização agrícola. A estratificação das unidades a serem pesquisadas por tipo de subprojeto teve por base sua classificação como boa, regular e ruim, conforme extensionistas que acompanham os projetos e profissionais do corpo técnico responsáveis pelo Programa de Combate à Pobreza Rural / Projeto São José.

Por sua vez, na seleção das comunidades, foram utilizados os seguintes critérios: o tipo do subprojeto e a distribuição geográfica das comunidades. Desta forma, a amostra ficou distribuída conforme Tabela 1.

Tabela 1 - Tamanho e distribuição da amostra por tipo de subprojeto analisado no Estado do Ceará, 2002.

\begin{tabular}{l|c|c}
\hline \multicolumn{1}{c|}{ Subprojeto } & № de Comunidades & № de Beneficiários \\
\hline Abastecimento de água & 7 & 14 \\
Eletrificação rural & 8 & 16 \\
Mecanização agrícola & 6 & 12 \\
Ação fundiária & 6 & 12 \\
\hline Total & 27 & 54 \\
\hline
\end{tabular}

Fonte: Dados da pesquisa

É importante notar que não foi objetivo deste estudo utilizar uma amostra que seja estatisticamente significante relativamente à população beneficiada, mas que possa oferecer uma indicação da direção e magnitude dos efeitos do Projeto.

\section{Resultados e discussão}

A seguir será apresentada a eficácia do programa e o comportamento dos principais indicadores socioecômicos analisados.

\subsection{Eficácia do Programa}

A Tabela 2 apresenta a eficácia do PSJ. Verifica-se que somente parte dos projetos previstos, inicialmente, foi aprovada e financiada o que demonstra que, em princípio, a meta estabelecida não foi cumprida, ou seja, a eficácia foi somente de $71,69 \%$, contudo, este fato pode ser 
justificado pela mudança que houve ao longo do período na tipologia dos subprojetos liberados, o que acarretou maiores despesas e, conseqüentemente, redução no número de projetos financiados.

Com relação ao valor do investimento a eficácia foi de $100 \%$, o que indicou que o valor previsto inicialmente foi totalmente aplicado no PSJ. Referido programa tinha como meta abranger 176 municípios, entretanto, ampliou para 177 municípios, mostrando uma eficácia de 100,60\%. No que diz respeito ao número de famílias beneficiadas, a meta reformulada em 1998, era de 135.000, havendo incremento para 189.363 famílias o que demonstra uma eficácia de 140,27\%. Estes resultados podem ser atribuídos à ampliação no número de sub-projetos de abastecimento de água e eletrificação rural que beneficiaram um número maior de famílias em relação aos sub-projetos de mecanização agrícola e ação fundiária.

Tabela 2 - Eficácia do PSJ em relação ao número de subprojetos, valor total do financiamento, número de municípios, número de famílias beneficiadas no Estado do Ceará, nos anos de 1996-2001.

\begin{tabular}{l|c|c|c}
\hline Discriminação & $\begin{array}{c}\text { Meta } \\
(\mathrm{A})\end{array}$ & $\begin{array}{c}\text { Realização } \\
(\mathrm{B})\end{array}$ & $\begin{array}{c}\text { Eficácia } \\
(\mathrm{B} / \mathrm{A}) \times 100\end{array}$ \\
\hline Número de subprojetos & 4.260 & 3054 & 71,69 \\
Valor total (US\$ 1000,00) & 93.198 .545 & 93.198 .545 & 100,00 \\
Número de Municípios & 176 & 177 & 100,60 \\
Número de famílias beneficiadas & 135.000 & 189.363 & 140,27 \\
\hline
\end{tabular}

Fonte: Elaboração própria com base em planilhas de dados da Secretaria Desenvolvimento Rural - Estado do Ceará

\subsection{Educação}

A Tabela 3 apresenta a variação no número de pessoas das famílias entrevistadas por categoria de escolaridade. Entre o grupo de pessoas acima de sete anos de idade, de acordo com teste Mann-Whitney U, ocorreram variações significativas no número de pessoas inseridas nas seguintes categorias de escolaridade: Só lê e escreve ( $\alpha=1,5 \%$ ); Ensino fundamental ( $1^{\mathrm{a}}$ a $4^{\mathrm{a}}$ sérire) completo $(\alpha=0,6 \%)$; Ensino fundamental ( $5^{\mathrm{a}}$ a $8^{\mathrm{a}}$ série) completo $(1,7 \%)$ e Ensino médio incompleto $(\alpha=6,9 \%)$. 
1042 - Eficácia e evolução dos indicadores socioeconômicos de famílias beneficiadas pelo programa de combate à pobreza rural /Projeto São José no Estado do Ceará

Quando se observa o grupo de pessoas acima de 18 anos as mudanças na escolaridade dos membros das famílias entrevistadas são ainda menos perceptíveis. Apenas as categorias “só lê e escreve” $(\alpha=1,5 \%)$ e Ensino fundamental ( $1^{\mathrm{a}}$ a $4^{\mathrm{a}}$ série) completo ( $\left.\alpha=5,5 \%\right)$ apresentaram variações significativas. A queda na categoria "só lê e escreve" pode ser atribuída a programas educacionais rurais, alfabetização de jovens e adultos e acesso a aulas noturnas propiciado pela eletrificação rural que possibilitou parte dos jovens e adultos, que trabalhavam durante o dia, freqüentassem a escola no período noturno. Por outro lado, a diminuição no número de pessoas pertencentes à categoria Ensino fundamental ( $1^{\mathrm{a}}$ a $\left.4^{\mathrm{a}}\right)$ completo pode ser explicada pela transferência de alunos para a categoria seguinte, ensino fundamental ( $5^{\mathrm{a}}$ a $8^{\mathrm{a}}$ série) incompleto.

O baixo nível de escolaridade dos membros das famílias entrevistadas reflete uma situação que é muito comum no meio rural nordestino. Isto é um reflexo direto de falta de oportunidades educacionais que ocorreram em décadas passadas e que afetou principalmente as gerações mais velhas, nas quais se encontra a maior parcela de analfabetos formais. Enquanto isso as gerações mais novas são afetadas por insuficiência de escolaridade. Constituíram-se, assim, um enorme contingente de pessoas subescolarizadas que aprendem mais pela repetição do que por replicação das competências básicas e que se encontram nas franjas menos produtivas e mais pobres da sociedade.

A melhoria no nível educacional pode ser significativa em longo prazo, desde que sejam feitos investimentos na construção de creches, escolas de ensino fundamental e médio, escolas técnicas e capacitação de professores já contratados, além da contratação de outros professores por via de concursos públicos e salários competitivos com os profissionais do setor urbano. 
Tabela 3 - Freqüência absoluta e relativa dos membros das famílias dos beneficiários dos subprojetos selecionados, com idade acima se 7 anos e acima de 18 anos, segundo o nível de escolaridade no Ceará, nos anos de 1998 e 2001.

\begin{tabular}{|c|c|c|c|c|c|}
\hline \multirow[t]{2}{*}{$\begin{array}{l}\text { Escolaridade } \\
\text { (Pessoas acima de } 7 \text { anos) }\end{array}$} & \multicolumn{2}{|c|}{1998} & \multicolumn{2}{|c|}{2001} & $\begin{array}{l}\text { Teste Mann } \\
\text {-Whitney-U }\end{array}$ \\
\hline & $\mathrm{N}^{\mathrm{o}}$ & $\%$ & $\mathrm{~N}^{\mathrm{o}}$ & $\%$ & Sig. \\
\hline Analfabeto & 16 & 7,1 & 12 & 5,3 & 0,429 \\
\hline Assina o nome & 34 & 15,0 & 35 & 15,4 & 0,808 \\
\hline Só lê e escreve** & 22 & 9,7 & 9 & 4,0 & $0, .015$ \\
\hline Ensino fund. ( $1^{\mathrm{a}}$ a $4^{\mathrm{a}}$ série) incompleto & 62 & 27,5 & 58 & 25,5 & 0,654 \\
\hline Ensino fund. ( $1^{\text {a }}$ a $4^{\text {a }}$ série) completo* & 27 & 11,9 & 11 & 4,8 & 0,006 \\
\hline Ensino fund. ( $5^{\mathrm{a}}$ a $8^{\mathrm{a}}$ série) incompleto & 38 & 16,8 & 50 & 22,0 & 0,161 \\
\hline Ensino fund. ( $5^{\mathrm{a}}$ a $8^{\mathrm{a}}$ série) completo* & 4 & 1,8 & 14 & 6,2 & 0,017 \\
\hline Ensino Médio incompleto $* * *$ & 11 & 4,9 & 21 & 9,4 & 0.069 \\
\hline Ensino Médio completo & 12 & 5,3 & 17 & 7,4 & 0.344 \\
\hline Total de pessoas & 226 & 100,0 & 227 & 100,0 & \\
\hline \multicolumn{6}{|l|}{$\begin{array}{l}\text { Escolaridade } \\
\text { (Pessoas acima de } 18 \text { anos) }\end{array}$} \\
\hline Analfabeto & 14 & 9,6 & 12 & 8,5 & 0,751 \\
\hline Assina o nome & 32 & 21,9 & 35 & 24,8 & 0,562 \\
\hline Só lê e escreve** & 21 & 14,4 & 8 & 5,7 & 0,015 \\
\hline Ensino fund. ( $1^{\mathrm{a}}$ a $4^{\mathrm{a}}$ série) incompleto & 33 & 22,7 & 31 & 22,0 & 0,989 \\
\hline Ensino fund. ( $1^{\text {a }}$ a $4^{\text {a }}$ série) completo ${ }^{* * *}$ & 10 & 6,8 & 3 & 2,1 & 0,055 \\
\hline Ensino fund. ( $5^{\mathrm{a}}$ a $8^{\mathrm{a}}$ série) incompleto & 13 & 8,9 & 20 & 14,2 & 0,162 \\
\hline Ensino fund. ( $5^{\mathrm{a}}$ a $8^{\mathrm{a}}$ série) completo & 4 & 2,7 & 6 & 4,3 & 0,485 \\
\hline Ensino Médio incompleto & 8 & 5,5 & 10 & 7,1 & 0,574 \\
\hline Ensino Médio completo & 11 & 7,5 & 16 & 11,3 & 0,269 \\
\hline Total de pessoas & 146 & 100,0 & 141 & 100,0 & \\
\hline
\end{tabular}

Fonte: Dados da pesquisa. * Significativa a $1 \% ;{ }^{* *}$ Significativa a $2 \% ;{ }^{* * *}$ Significativa a $10 \%$

\subsection{Saúde}

Assegurar à população o direito à saúde através de ações governamentais é de grande importância para a promoção do bem-estar social. Se não há acesso a esse direito social e universal não há cidadania.

As informações presentes na Tabela 4 demonstram que, em geral, a saúde das famílias entrevistadas apresentou melhoria significativa em 2001, comparativamente à saúde das famílias no ano de 1998. Houve queda no número de pessoas com doenças nos últimos seis meses. Observa-se que houve uma redução drástica no número de pessoas que sofriam com diarréia. Ademais, nenhuma pessoa, nos seis meses antes da última entrevista, acusou problemas causados por verminose e hepatite. Verificou-se, ainda, 
que as famílias entrevistadas nas comunidades beneficiadas pelo subprojeto de abastecimento d'água não apresentaram nenhum tipo de doença grave. Grande parte dos beneficiários dos subprojetos de abastecimento de água apontou a disponibilidade e a qualidade da água como fundamentais para melhoria da saúde da família; enquanto isso, os beneficiários dos subprojetos de eletrificação consideram como benefícios secundários, a melhoria da saúde das famílias, em razão da possibilidade de preservar os alimentos e a maior facilidade de atendimento médico em postos de saúde da comunidade, especialmente atendimento odontológico.

Pode-se afirmar, ainda, com a probabilidade de erro correspondente a 0,01 que houve uma diminuição no número de doenças por família no ano de 2001 em relação ao ano de $1998^{1}$.

Durante as entrevistas, foram mencionadas outras ações do governo estadual que devem ter contribuído parcialmente para este resultado, como a contratação de agentes de saúde e o Programa Médico da Família. Com base nas informações do IPLANCE (2001), houve também redução na taxa de mortalidade infantil em 2000 relativamente a 1998.

Tabela 4 - Freqüência relativa das famílias dos beneficiários dos subprojetos selecionados, segundo a existência e o tipo de doenças ocorridas nos últimos seis meses no Estado do Ceará, nos anos de 1998 e 2001.

\begin{tabular}{l|c|c|c}
\hline \multicolumn{1}{c|}{ Doenças } & $\begin{array}{c}1998 \\
\%\end{array}$ & $\begin{array}{c}2001 \\
\%\end{array}$ & $\begin{array}{c}\text { Teste Mann Whitney-U } \\
\text { Sig. }\end{array}$ \\
\hline - Pessoas com doença(s) nos últimos 6 meses** & 23,8 & 8,6 & 0,040 \\
- Pessoas sem doença(s) nos últimos 6 meses** & 76,2 & 91,4 & 0,040 \\
- Principais patologias + & & & \\
- Catapora & 0,0 & 2,3 & 0,317 \\
- Hepatite* & 0,4 & 0,0 & 1,000 \\
- Diarréia* & 19,7 & 0,8 & 0,004 \\
- Verminose*** & 4,8 & 0,0 & 0,080 \\
- Outros + + & 3,3 & 5,1 & 0,649 \\
\hline Número médio de doenças por famílias*** & 1,4 & 0,4 & \\
\hline
\end{tabular}

Fonte: Dados da pesquisa

+ A soma dos percentuais das principais patologias no ano de 1998 é superior a 23,8, em razão de uma mesma pessoa ter apresentado mais de uma doença.

++ Asma, alergias, osteoporose, dengue etc.

* Significativa a $1 \%$; ** Significativa a $5 \%$; ** Significativa a $10 \%$

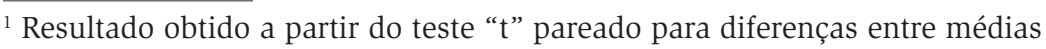




\subsection{Características dos Domicílios}

Os resultados expressos na Tabela 5 indicam que não houve mudanças significativas nos domicílios das famílias dos beneficiados selecionados quanto aos aspectos: material utilizado na construção das paredes e pisos e fonte de iluminação. Apesar de ter sido constatada uma queda no número de famílias que usavam lamparinas, lampiões etc. Tal redução não foi significativa no período analisado. Quanto à situação das instalações sanitárias houve um aumento de 16,6\% em 1998 para 40,7\% em 2001 no número de fossas sépticas nas residências dos beneficiários. Esse incremento foi maior nas famílias com subprojetos de abastecimento de água e eletrificação rural. Por outro lado, houve queda na utilização de fossas rudimentares, de 51,9\% para 35,2\% no referido período.

Em relação ao abastecimento d'água pode-se afirmar, com um nível de significância de $2,4 \%$, que houve um aumento no número de residências que passaram a utilizar este tipo de abastecimento. Constatouse ainda queda significativa entre as famílias entrevistadas que utilizam água tratada com cloro, embora, tenha aumentado a proporção dos beneficiados que utilizavam apenas água filtrada.

O acesso à iluminação elétrica foi outro fator que contribuiu para a melhoria das habitações ao longo do período estudado. Constatou-

se nas entrevistas que houve uma redução do número de famílias que usavam lamparinas, lampiões etc. 
Tabela 5 - Características dos domicílios das famílias dos beneficiários nos subprojetos selecionados no Ceará, nos anos de 1998 e 2001.

\begin{tabular}{|c|c|c|c|}
\hline Características & 1998 & 2001 & $\begin{array}{c}\text { Teste Mann } \\
\text { Whitney-U } \\
\text { Sig. }\end{array}$ \\
\hline 1. Paredes (\%) & 100,0 & 100,0 & \\
\hline - Alvenaria & 81,4 & 83,3 & 0,801 \\
\hline - Taipa não revestida & 5,6 & 7,4 & 0,801 \\
\hline - Taipa revestida & 13,0 & 9,3 & 0,542 \\
\hline 2. Piso (\%) & 100,0 & 100,0 & \\
\hline - Cimento ou cerâmica & 85,2 & 90,7 & 0,377 \\
\hline - Tijolo & 3,7 & 5,6 & 0,649 \\
\hline - Barro & 11,1 & 3,7 & 0,144 \\
\hline 3. Esgoto (instalação sanitária) (\%) & 100,0 & 100,0 & \\
\hline - Fossa séptica* & 16,6 & 40,7 & 0,006 \\
\hline - Fossa rudimentar*** & 51,9 & 35,2 & 0,082 \\
\hline - Outra & 0,0 & 1,9 & 0,317 \\
\hline - Não tem & 24,1 & 22,2 & 0,820 \\
\hline - Não soube responder** & 7,4 & 0,0 & 0,042 \\
\hline 4. Abastecimento d'água (\%) & 100,0 & 100,0 & \\
\hline - Rede geral** & 9,3 & 25,9 & 0,024 \\
\hline - Poço ou nascente & 66,7 & 53,7 & 0,171 \\
\hline - Outro & 20,4 & 20,4 & 1,000 \\
\hline - Não tem & 1,8 & 0,0 & 0,317 \\
\hline - Não soube responder & 1,8 & 0,0 & 0,317 \\
\hline 5. Qualidade da água (\%) & 100,0 & 100,0 & \\
\hline - Clorada*** & 37,0 & 22,2 & 0,093 \\
\hline - Filtrada* & 13,0 & 42,6 & 0,001 \\
\hline - Coada & 44,5 & 29,6 & 0,0113 \\
\hline - Sem tratamento & 3,7 & 5,6 & 0,649 \\
\hline - Não soube responder & 1,8 & 0,0 & 0,317 \\
\hline 6 Iluminação (\%) & 100,0 & 100,0 & \\
\hline - Com iluminação elétrica & 77,8 & 87,0 & 0,208 \\
\hline - Sem iluminação elétrica & 22,2 & 13,0 & 0,208 \\
\hline 7 Lixo (\%) + & - & 100,0 & \\
\hline - Coletado pela Prefeitura & - & 7,4 & \\
\hline - Queimado ou enterrado & - & 38,9 & \\
\hline - Jogado na superfície do solo & - & 53,7 & \\
\hline
\end{tabular}

Fonte: Dados da pesquisa

+ Esta informação não foi coletada pelos entrevistadores em 1998.

* Significativa a $1 \%$;* Significativa a $5 \%$;** Significativa a $10 \%$ 


\subsection{Bens Duráveis}

As informações contidas na Tabela 6 indicam que, em geral, não houve um aumento no número de famílias com acesso aos bens duráveis após 1998. As exceções observadas foram as motocicletas, (128,6\%), liquidificador $(46,2 \%)$ e refrigerador $(42,3 \%)$, em nível de significância de $5 \%$. Assim, segundo o resultado do teste de Mann-Whitney U observou-se que, grosso modo, não houve incremento significativo dos bens duráveis.

Tabela 6 - Freqüência absoluta e relativa das famílias dos beneficiários dos subprojetos selecionados, segundo a obtenção dos bens duráveis no Ceará, nos anos de 1998 e 2001.

\begin{tabular}{l|c|c|c|c|c|c|c}
\hline \multirow{2}{*}{ Bens Duráveis } & \multicolumn{2}{|c|}{1998} & \multicolumn{2}{c|}{2001} & \multicolumn{2}{c|}{ Variação } & $\begin{array}{c}\text { Teste Mann } \\
\text { Whitney U }\end{array}$ \\
\cline { 2 - 8 } & $\mathrm{N}^{\circ}$ & $\%$ & $\mathrm{~N}^{\circ}$ & $\%$ & $\mathrm{~N}^{\circ}$ & $\%$ & Sig. \\
\hline 1. Fogão a gás & 48 & 88,9 & 52 & 96,3 & 4 & 8,3 & 0,144 \\
2. Refrigerador** & 26 & 48,1 & 37 & 68,5 & 11 & 42,3 & 0,330 \\
3. Freezer & 5 & 9,3 & 6 & 11,1 & 1 & 20,0 & 0,751 \\
4. Ferro elétrico & 31 & 57,4 & 37 & 68,5 & 6 & 19,4 & 0,234 \\
5. Liquidificador** & 26 & 48,1 & 38 & 70,4 & 12 & 46,2 & 0,019 \\
6. Máquina de costura & 21 & 38,9 & 25 & 46,3 & 4 & 19,0 & 0,438 \\
7. Rádio & 47 & 87,0 & 45 & 83,3 & -2 & $-4,3$ & 0,590 \\
8. Aparelho de som & 22 & 40,7 & 26 & 48,1 & 4 & 18,2 & 0,441 \\
9. Televisor & 45 & 83,3 & 48 & 88,9 & 3 & 6,7 & 0,406 \\
10. Antena parabólica & 15 & 27,8 & 22 & 40,7 & 7 & 46,7 & 0,158 \\
11. Bicicleta & 44 & 81,5 & 46 & 85,2 & 2 & 4,5 & 0,607 \\
12. Moto** & 7 & 13,0 & 16 & 29,6 & 9 & 128,6 & 0,035 \\
14. Carro & 4 & 7,4 & 6 & 11,1 & 2 & 50,0 & 0,509 \\
\hline
\end{tabular}

Fonte: Dados da pesquisa. ${ }^{* *}$ Significativa a $5 \%$

Apesar de ter havido um pequeno incremento no número de famílias com a aquisição de televisores $(6,7 \%)$, tal variação não foi significativa, verificou-se que, na realidade, parte das famílias relataram que fizeram a substituição dos televisores que funcionavam à bateria por aparelhos à energia, especialmente, nos projetos de eletrificação rural.

Chama-se atenção para o fato de que o impacto deste programa relativamente à acumulação de bens duráveis poderia ter sido maior que o 
indicado nas tabelas (especialmente para o caso dos subprojetos de eletrificação rural), uma vez que, na época do primeiro levantamento dos dados, em 1998, os subprojetos já haviam sido implantados nas comunidades e parte da população já havia adquirido referidos bens. Desta forma, não se pôde identificar o real incremento dos bens duráveis.

\subsection{Origem e caracterização das rendas das famílias dos beneficiários}

As Tabelas 7, 8, 9 e 10, referem-se aos rendimentos das famílias dos beneficiários entrevistados neste estudo. Verifica-se que, dentre as opções da obtenção da renda das famílias, a que proporciona o maior montante é a renda gerada na ocupação habitual, independente do tipo de subprojeto, como apresentado na Tabela 7.

Os dados apresentados na Tabela 8 indicam que a renda bruta mensal por família na ocupação habitual nas comunidades beneficiadas apresentou um acréscimo de, aproximadamente, $79 \%$ entre os anos de estudo. Com base em dados do Instituto de Planejamento do Ceará (IPLANCE, 2002) o valor real do PIB agrícola do estado aumentou em $3,7 \%$ em 2000, relativamente ao ano de 1998 .

$\mathrm{O}$ teste $\mathrm{t}$ foi utilizado para testar a significância da diferença entre as médias das rendas mensais mencionadas nos anos em estudo. $\mathrm{O}$ valor de " $t$ " indicou, ao nível de significância de $8 \%$ (teste bicaudal), que a renda bruta média mensal na ocupação habitual por família para a amostra total no ano de 2001 foi maior (78,5\%) que a renda no ano de 1998. Este teste foi realizado levando-se em consideração que as variâncias nos dois anos são diferentes, como indicado pelo teste $\mathrm{F}$ emível de significância de 1\%. Estas rendas por tipo de subprojeto não foram diferentes a esse nível de significância.

A Tabela 9 indica que a renda média bruta das famílias beneficiadas pelos subprojetos do PCPR/PSJ aumentou, aproximadamente, 90\% no período analisado. 
Tabela 7 - Origem e montante das rendas das famílias dos beneficiários nos subprojetos selecionados no Ceará, nos anos de 1998 e 2001 *.

\begin{tabular}{l|c|c|c|c}
\hline \multicolumn{1}{c|}{ Origem da Renda } & \multicolumn{2}{c|}{1998} & \multicolumn{2}{c}{2001} \\
\hline \multirow{3}{*}{ Ocupação habitual } & $\mathrm{R} \$$ & $\%$ & $\mathrm{R} \$$ & $\%$ \\
\cline { 2 - 5 } Outra atividade & 226,5 & 73,6 & 404,4 & 69,2 \\
Pensões & 42,2 & 13,7 & 61,6 & 10,5 \\
Aluguéis & 37,7 & 12,3 & 93,3 & 16,1 \\
Doações & 0,0 & 0,0 & 5,4 & 0,9 \\
Bolsas & 1,3 & 0,4 & 6,4 & 1,1 \\
\hline Total & 0,0 & 0,0 & 13,1 & 2,2 \\
\hline
\end{tabular}

Fonte: Dados da pesquisa

* Todos os valores monetários estão expressos em valores de 2001 com base no INPC, IBGE.

Tabela 8 - Renda bruta mensal por família dos beneficiários na ocupação habitual nos diferentes subprojetos no Ceará, nos anos de 1998 e 2001.

\begin{tabular}{l|c|c|c}
\hline \multirow{2}{*}{ Subprojeto } & \multicolumn{3}{|c}{$\begin{array}{c}\text { Renda Bruta Mensal das Famílias na } \\
\text { Ocupação Habitual + }\end{array}$} \\
\hline \multirow{3}{*}{ Mecanização agrícola } & $1998(\mathrm{R} \$)$ & $2001(\mathrm{R} \$)$ & Variação (\%) \\
\cline { 2 - 4 } Ação fundiária & 347,9 & 295,5 & $-15,1$ \\
Abastecimento d’água & 135,3 & 455,7 & $236,8^{*}$ \\
Eletrificação rural & 280,3 & 400,6 & 42,9 \\
\hline Amostra Total & 156,7 & 450,2 & $187,3^{*}$ \\
\hline
\end{tabular}

Fonte: Dados da pesquisa

+ Todos os valores monetários estão expressos em valores de 2001 com base no INPC, IBGE.

*A diferença das médias é significante ao nível de $5 \%$ (teste "t" de Student).

** A diferença das médias é significante ao nível de $8 \%$ (teste " $t$ " de Student).

Tabela 9 - Renda bruta total mensal por família dos beneficiários sem considerar a parcela do auto consumo nos subprojetos selecionados no Ceará, nos anos de 1998 e 2001.

\begin{tabular}{l|c|c|c}
\hline \multicolumn{1}{c|}{ Subprojeto } & \multicolumn{3}{|c}{ Renda Bruta Total por Família + } \\
\hline \multirow{3}{*}{ Mecanização agrícola } & $1998(\mathrm{R} \$)$ & $2001(\mathrm{R} \$)$ & Variação (\%) \\
\cline { 2 - 4 } Ação fundiária & 451,61 & 576,00 & 27,5 \\
Abastecimento d'água & 235,03 & 577,30 & $145,6^{*}$ \\
Eletrificação rural & 367,94 & 545,10 & 48,1 \\
\hline Amostra Total & 201,64 & 629,1 & $211,9^{*}$ \\
\hline
\end{tabular}

Fonte: Dados da pesquisa

+ Renda bruta mensal inclui renda na ocupação habitual, renda de outras ocupações, pensões, aluguéis, doações, bolsa renda e bolsa escola. Todos os valores monetários estão expressos em valores de 2001 com base no INPC, IBGE.

* A diferença das médias é significante ao nível de 1\% (teste " $\mathrm{t}$ " de Student). 
Eficácia e evolução dos indicadores socioeconômicos de famílias beneficiadas pelo programa de combate à pobreza rural/Projeto São José no Estado do Ceará

O resultado do teste estatístico, com nível de significância de 1\% (considerando que a variância da renda bruta total mensal por família é diferente nos anos de 1998 e 2001), indica que a renda bruta total mensal por família, para a amostra como um todo,no ano de 2001 foi diferente da respectiva renda no ano de 1998. Entretanto, a renda real per capita no setor rural apresentou tendência negativa a partir de 1996 com exceção do ano 2000 (IPLANCE, 2001). Deve-se esclarecer que o Produto Interno Bruto (PIB) agrícola nominal do Ceará cresceu 15,5\%, o que corresponde em valores reais a 3,7\% entre 1998 e 2000 , enquanto que a renda agrícola per capita nominal aumentou $16,6 \%$, ou seja, $4,7 \%$ em termos reais. Neste período, a população rural cearense decresceu 9,32\% . Como a população rural decresceu a renda agrícola nominal e/ ou real per capita é pouco menor do que o decréscimo do PIB agrícola nominal e/ou real no ano de 2001 (neste ano o PIB agrícola é inferior ao do ano 2000, em razão de ter sido um ano de seca).

Mesmo que a renda agrícola não seja a única fonte de renda das populações rurais - pelo contrário, sabe-se que vem aumentando a importância da renda não agrícola entre esses habitantes - esta, ainda, é importante fonte de renda destas famílias. Uma comparação da variação estimada da renda per capita rural no Ceará com a variação de renda do trabalho na ocupação habitual dos beneficiários entrevistados (Tabela 7), mostra que a diferença ainda é bastante alta, de, no mínimo, $73 \%$ a mais no grupo dos beneficiários. Sabe-se que o PIB total do estado cresceu entre os anos de 1998 e 2000, 16,3\% em termos nominais e 4,5\% em valores reais, e que a renda bruta - exceto o autoconsumo por família dos beneficiários - cresceu, aproximadamente, 90\% em termos reais entre 1998 e 2001. Com base nestas informações fica evidente que os números obtidos da amostra dos beneficiários sobre o aumento da renda no período supera bastante a variação da renda rural do estado como um todo.

As informações apresentadas na Tabela 10 mostram que no ano 2001 a renda bruta e a renda líquida mensal per capita foram de $\mathrm{R} \$ 123,20$ e $\mathrm{R} \$ 102,20$, respectivamente, o que corresponde a mais do dobro da renda real mensal per capita do setor rural cearense (IPLANCE, 2001).

Deve-se mencionar que além dos benefícios já referidos foi explicitada, no momento das entrevistas, a satisfação dos beneficiários advinda dos subprojetos que permitiram, no caso do subprojeto de energia, 
usufruir luz elétrica, utilizar aparelhos eletrodomésticos, a implantação de postos médicos e a realização de aulas noturnas. Para aqueles que obtiveram projetos de abastecimento passaram a ter água em seus domicílios nas quantidades desejadas e sem gasto de tempo para obtê-las. Para os beneficiários dos subprojetos de mecanização agrícola possibilitou cultivar com menos sacrifício, maior quantidade de área, e, no caso dos subprojetos de ação fundiária os beneficiários passaram a trabalhar em terras que lhes pertenciam e que ficarão para seus descendentes.

Tabela 10 - Classificação da renda mensal das famílias dos beneficiários nos subprojetos selecionados no Ceará, no ano de $2001+$.

\begin{tabular}{|c|c|c|c|c|c|c|}
\hline \multirow[b]{2}{*}{ Subprojeto } & \multicolumn{6}{|c|}{2001} \\
\hline & $\begin{array}{c}\text { Renda } \\
\text { Bruta } \\
\text { Mensal } \\
\text { por } \\
\text { Família } \\
(\mathrm{R} \$)++\end{array}$ & $\begin{array}{c}\text { Renda } \\
\text { Bruta } \\
\text { Mensal } \\
\text { Per capita } \\
\text { (R\$) }\end{array}$ & $\begin{array}{c}\text { Renda } \\
\text { Líquida } \\
\text { Mensal por } \\
\text { Família } \\
(\mathrm{R} \$)+++\end{array}$ & $\begin{array}{c}\text { Renda } \\
\text { Líquida } \\
\text { Mensal } \\
\text { Per capita } \\
\text { (R\$) + + + }\end{array}$ & $\begin{array}{c}\text { Renda Bruta } \\
\text { Mensal (R\$) } \\
\text { (incluindo o } \\
\text { autoconsumo) }\end{array}$ & $\begin{array}{l}\text { Renda Bruta } \\
\text { Mensal Per } \\
\text { capita (R\$) } \\
\text { (incluindo o } \\
\text { autoconsu- } \\
\text { mo) }\end{array}$ \\
\hline $\begin{array}{l}\text { Mecanização } \\
\text { agrícola }\end{array}$ & 629,5 & 119,9 & 576,0 & 109,7 & 678,2 & 129,2 \\
\hline Ação fundiária & 577,3 & 110,0 & 458,0 & 87,2 & 634,4 & 120,8 \\
\hline $\begin{array}{l}\text { Eletrificação } \\
\text { rural }\end{array}$ & 629,1 & 132,4 & 429,5 & 90,4 & 685,0 & 144,2 \\
\hline $\begin{array}{l}\text { Abastecimento } \\
\text { d'água }\end{array}$ & 545,1 & 141,3 & 445,1 & 115,4 & 589,7 & 152,9 \\
\hline Amostra Total & 584,0 & 123,2 & 484,3 & 102,2 & 647,5 & 136,6 \\
\hline
\end{tabular}

Fonte: Dados da pesquisa

+ Todos os valores monetários estão expressos em valores de 2001 com base no INPC, IBGE.

++ Não inclui o autoconsumo.

+++ No cálculo da renda líquida não foram considerados o custo da mão-de-obra familiar e o custo de oportunidade da terra.

\section{Conclusões e sugestões}

Com base no exposto pode-se chegar a algumas conclusões:

- Com relação à educação não houve mudanças significativas entre os dois períodos em estudo, com exceção para uma queda no número de pessoas que só sabe ler e escrever e o número de pessoas que concluíram o ensino fundamental ( $1^{\mathrm{a}}$ a $4^{\mathrm{a}}$ série) as quais devem ingressar em outra categoria de escolaridade. 
- Melhorias nas condições de saúde com redução do número de pessoas acometidas por doenças e nas condições de habitação, com destaque para o incremento substancial do número de fossas sépticas nas residências das famílias pesquisadas;

- Foram observadas melhorias nas residências (esgotos, abastecimento de água, qualidade de água) e um incremento significativo de alguns bens duráveis adquiridos pelas famílias entrevistadas entre os anos analisados. A renda das famílias aumentou, sendo que o item que mais contribuiu para o incremento desta renda foi a ocupação habitual. Chama a atenção o fato de que a renda per capita das famílias entrevistadas é bastante superior à renda per capita da população rural do estado.

- As família pesquisadas declararam ter havido melhorias de bem estar advindas de subprojetos, em especial, de energia e de abastecimento de água.

Sugere-se que haja intensificação do acompanhamento dos subprojetos financiados com recursos do PCPR/PSJ para garantir a operação e manutenção adequada e, conseqüentemente, garantir maior benefício dos investimentos feitos.

Considera-se importante propiciar alguns cursos relativos a associativismo para todos os beneficiários e sobre organização, especialmente, para os dirigentes ou líderes comunitários através de organizações cooperativistas do estado com experiência nessa área.

Sugere-se, por fim, um estudo detalhado sobre geração de emprego e renda advindos dos investimentos feitos nos subprojetos do PCPR/PSJ.

\section{Referências bibliográficas}

BANCO MUNDIAL. Relatório sobre o Desenvolvimento Mundial 2000/ 2001. Luta contra a pobreza.(2001) Disponível em: < http//www. worldbank.org.poverty/portuguese/wdr/index.htm > . Acesso em: 21.03.02.

CEARÁ. SECRETARIA DE DESENVOLVIMENTO RURAL-SDR. Desempenho 1995-1998. Fortaleza, 1998. 76p.

INSTITUTO DE PLANEJAMENTO DO CEARA. Anuário estatístico do Ceará. Fortaleza: IPLANCE, 2000 
Anuário Estatístico do Ceará. Fortaleza: IPLANCE, 2001. Anuário Estatístico do Ceará. Fortaleza: IPLANCE, 2002.

MACHADO, L. S. et al. A ação do Banco do Nordeste do Programa Nacional de Fortalecimento da Agricultura Familiar (PRONAF) sob o enfoque do Desenvolvimento Local. In: Agricultura Familiar: Desafios para a sustentabilidade. Coletânea. Embrapa - CPATC, SDR/MA, 1998,276 p.

Recebido em setembro de 2006 e revisto em março de 2007. 